\title{
Grafting of acrylonitrile onto cellulosic material derived from bamboo (Dendrocalamus strictus)
}

\author{
R. Khullar ${ }^{1}$, V. K. Varshney ${ }^{*}$, S. Naithani ${ }^{2}$, P. L. Soni ${ }^{1}$ \\ ${ }^{1}$ Centre for Advanced Studies in Chemistry of Forest Products, Forest Research Institute, P.O. New Forest, \\ Dehra Dun 248 006, India \\ ${ }^{2}$ Cellulose and Paper Division, Forest Research Institute, P.O. New Forest, Dehra Dun 248 006, India
}

Received 3 April 2007; accepted in revised form 21 October 2007

\begin{abstract}
Bamboo, a lignocellulosic biopolymer material, is of interest as feedstock for production of cellulose derivatives by chemical functionalization. Optimization of grafting of acrylonitrile onto cellulosic material (average Degree of Polymerization 816), isolated from bamboo (Dendrocalamus stictus) was performed by varying the process parameters such as duration of soaking of cellulosic material in ceric ammonium nitrate solution, ceric ammonium nitrate concentration, polymerization time, temperature of reaction and acrylonitrile concentration to study their influence on percent grafting and grafting efficiency.

Graft copolymerization of acrylonitrile onto cellulosic material derived from bamboo (Dendrocalamus strictus) in heterogenous medium can be initiated effectively with ceric ammonium nitrate. The optimum reaction conditions obtained for grafting of acrylonitrile onto cellulosic material were: duration of dipping cellulosic material in ceric ammonium nitrate solution $1 \mathrm{hr}$, ceric ammonium nitrate concentration $0.02 \mathrm{M}$, acrylonitrile concentration $24.6 \mathrm{~mol} /$ anhydroglucose unit, temperature of reaction $40^{\circ} \mathrm{C}$ and polymerization time $4 \mathrm{hrs}$. The percent grafting for optimized samples is $210.3 \%$ and grafting efficiency is $97 \%$. The characterization of the grafted products by means of FTIR and Scanning Electron Microscopy furnished the evidence of grafting of acrylonitrile onto the cellulosic material.
\end{abstract}

Keywords: biopolymers, cellulosic material, bamboo, grafting, acrylonitrile

\section{Introduction}

Biopolymers, being renewable raw materials, are gaining considerable importance because of the limited existing quantities of fossil supplies and the recent environment-conservative regulations [1]. In this regard, cellulose rich biomass acquires enormous significance as chemical feedstock, since it consists of cellulose, hemicellulose and lignin, which are biopolymers containing many functional groups suitable to chemical derivatization [2]. Eucalyptus cellulose and Musanga cecropioides wood have been modified into carboxymethyl cellulose (CMC) by Spasojevic et al. [3] and Akaranta et al. [4], respectively. Graft copolymerization of acrylonitrile and methyl methacrylate onto jute fibers and pineapple leaf fibers has been examined [5-8]. Low quality woods as well as industrial wastes of wood have been utilized to produce a thermoplastic material through cyanoethylation [9]. Recently conducted investigations on reactivity of fibers of Agave lechuguilla and Agave fourcroydes under chemical modification reactions like carboxymethylation, sulfation, acetylation, tritylation and subsequent carboxymethylation as well as oxidation, and grafting have demonstrated suitability of the agave fibers as a potential feed stock for producing cellulose derivatives for a variety of applications [10-12]. The goal of these modifications is 
to adjust the properties of biopolymer macromolecule for different purposes and to increase their consumption.

Bamboo belonging to the grass family Poaceae is an abundant renewable natural resource capable of production of maximum biomass per unit area and time as compared to counterpart timber species [13]. Since bamboo stem consists almost entirely of cellulose, hemicellulose (xylans, arabans, polyuronides etc.) and lignin [14], the biomass of bamboo can be used as a feedstock for production of a variety of cellulose derivatives for different broader applications by chemical modification.

Graft copolymerization of cellulose is a process in which attempts have been made to combine synthetic polymers with cellulose, to produce material with the best properties of both. This process is known as grafting, usually done by modifying the cellulose molecules through creation of branches of synthetic monomers that confer certain desirable properties on the cellulose without destroying its intrinsic properties [15].

Depending on the chemical structure of the monomer grafted onto cellulose, graft copolymers gain new properties such as hydrophilic and hydrophobic character, improved elasticity, water absorption, ion-exchange capability and heat resistance. These copolymers are finding applications for water treatment for textile industry, for reclaiming ions of precious metals, and for personal care products such as diapers etc. [16].

As a part of our ongoing programme on chemical modification of cellulose isolated from different sources [17-20], we were interested to study the derivatization of bamboo cellulose through substitution and grafting reactions. The present communication describes the optimization of the reaction conditions for grafting of acrylonitrile onto cellulosic material obtained from bamboo (Dendrocalamus strictus) using two-phase system by varying the reaction parameters such as the duration of soaking cellulosic material in CAN (ceric ammonium nitrate), concentration of CAN, polymerization time, temperature and concentration of acrylonitrile and studying their effects on $\% \mathrm{G}$ (percent grafting) and \%GE (percent grafting efficiency). Each of these parameters was varied one by one keeping other conditions constant in the reaction.

\section{Materials and methods}

\subsection{Materials}

Dendrocalamus strictus, a widely distributed and commonly cultivated bamboo in India was used for isolation of cellulose. Cellulose (yield 35\%) with following composition was isolated as per the standard Tappi method (TAPPI T2003 OM-88):

Cellulose 90.1; Hemicellulose 8.9; Lignin 0.4; Ash 0.6\%; Average Degree of Polymerization (DP) 816. Ceric ammonium nitrate (Aldrich Chemical Co., U.S.A.), nitric acid (AR grade, Rankem, India), toluene (LR grade, Rankem, India) and dimethyl formamide (AR grade, Rankem, India) were used without any purification. Acrylonitrile (LR grade, Rankem, India) was purified before use by extracting with $7 \%$ aqueous sodium hydroxide solution. The liquid monomer was then washed with distilled water several times, dried over anhydrous calcium chloride and distilled.

\subsection{Graft copolymerization}

The grafting reaction was carried out under nitrogen atmosphere in a three-necked flask equipped with a nitrogen inlet and a reflux condenser immersed in a constant temperature water bath (Remi, India $\pm 1^{\circ} \mathrm{C}$ ). Solution of CAN of varied concentrations were prepared by dissolving the required molar concentration of CAN salt in $1 \%$ nitric acid. In a typical reaction, $1 \mathrm{~g}$ cellulose was immersed in $30 \mathrm{ml}$ solution of CAN $(0.01-0.02 \mathrm{M})$ for a particular time $(0.5-2 \mathrm{hrs})$ followed by addition of a mixture of toluene $(20 \mathrm{ml})$ and acrylonitrile (12.3-30.7 mol/AGU). The reaction mixture was stirred using a magnetic stirrer. A continuous supply of nitrogen was maintained throughout the reaction period. The grafting reaction was carried out for varying periods of time (2-5 hrs) at varied temperatures $\left(20-50^{\circ} \mathrm{C}\right)$ under stirring using a magnetic stirrer. After the reaction was over, the reaction mixture was washed with distilled water, subsequently with methanol, filtered and the product was dried in the vacuum oven at $50^{\circ} \mathrm{C}$ for 4 days. The dried product was extracted with dimethylformamide for $48 \mathrm{hrs}$ to remove the homopolymer (polyacrylonitrile). The grafted cellulose was dried for 4 days to obtain a constant weight. The percent graft yield $(\% \mathrm{G})$ and percent grafting efficiency (\%GE) were calculated on an oven dry weight of cellulose from the increased weight of cellulose after grafting by using the Equations (1) and (2) [15]: 
$\% \mathrm{G}=\frac{\text { Final cellulose weight }- \text { Initial cellulose weight }}{\text { Initial cellulose weight }} \cdot 100$
$\% \mathrm{GE}=\frac{\text { Final cellulose weight }- \text { Initial cellulose weight }}{\text { Total polymer weight after reaction }- \text { Initial cellulose weight }} \cdot 100$

\subsection{IR analysis}

IR spectra of ungrafted and grafted cellulose were recorded on a JASCO FTIR-5300 spectrophotometer following the $\mathrm{KBr}$ disc technique in the range $4000-650 \mathrm{~cm}^{-1}$.

\subsection{Scanning Electron Microscopy (SEM) studies}

SEM images at 1000 and 5000 magnification were obtained for parent and grafted cellulosic material using Leo 435 VP scanning electron microscope (Cambridge, England). The fibers were laid down on the aluminium stub using a conductive tape and were sputter coated with gold.

\subsection{Water sorbency}

The water sorbency of the parent and grafted cellulosic material was determined according to the method described by Das et al. [21]. The water sorbency was expressed as the water-retention value (WRV) in grams of water per gram of the oven dry sample weight and was calculated as Equation (3):

\section{$\mathrm{WRV}[\mathrm{g} / \mathrm{g}]=(\mathrm{WET}-\mathrm{DRY}) / \mathrm{DRY}$}

where WET $=$ Weight of sample after immersing in water for $24 \mathrm{hrs}$, DRY = Dry weight of the sample.

\section{Results and discussion}

\subsection{Practical viewpoints}

Prompted by findings of the advantageous use of non-aqueous medium (toluene) on the grafting of acrylonitrile onto cotton cellulose [22, 23], a twophase system (aqueous initiator-toluene mixture) was used in this work also, which afforded high graft yields. Use of toluene inhibits diffusion of CAN out of the fiber, thus lessening homopolymer formation in the solution, and increases the availability of acrylonitrile, as reported by Gangnuex et al. [22] and Hon [23].

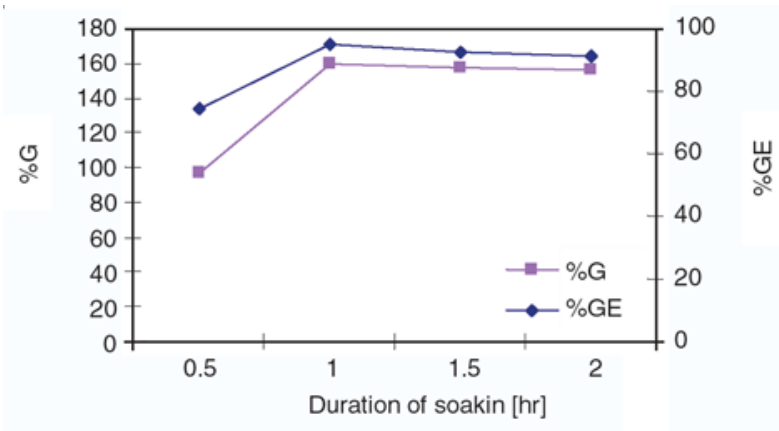

Figure 1. Effect of duration of soaking cellulosic material in CAN solution on $\% \mathrm{G}$ and $\% \mathrm{GE}$

\subsection{Effect of duration of soaking cellulosic material in CAN solution}

The effect of soaking time on $\% \mathrm{G}$ and $\% \mathrm{GE}$ is shown in Figure 1. It can be seen that the $\% \mathrm{G}$ and $\%$ GE increase rapidly with increase in time up to $1 \mathrm{hr}$ after which it levels off. Soaking time allows ceric solution to diffuse into cellulose fibers prior to grafting reaction thereby allowing initiation of free radicals on cellulose sample by oxidation with $\mathrm{Ce}^{\mathrm{IV}}$ ions. Initial increase in $\% \mathrm{G}$ and $\% \mathrm{GE}$ can be attributed to this factor [23]. Leveling off of $\% \mathrm{G}$ and $\% \mathrm{GE}$ on prolonging this soaking time beyond $1 \mathrm{hr}$ could be attributed to the decay of free radical activity of $\mathrm{Ce}^{\mathrm{IV}}$ oxidized cellulose resulting from the free radical termination by charge transfer. Similar trend has been observed by Hon [23] and Kulkarni and Mehta [24].

\subsection{Effect of ceric ammonium nitrate concentration}

Using standardized $1 \mathrm{hr}$ soaking time of cellulosic material in CAN solution, the effect of variation in CAN concentration was studied and the results are shown in Figure 2. CAN concentration was increased from $0.01-0.02 \mathrm{M}$. It is evident that both the grafting parameters, $\% \mathrm{G}$ and $\% \mathrm{GE}$ increase with an increase in the initiator concentration, but reaches maximum value of 159.7 and $95.1 \%$, respectively, at $0.02 \mathrm{M}$ of CAN. These increasing trends of the grafting parameters indicated that 


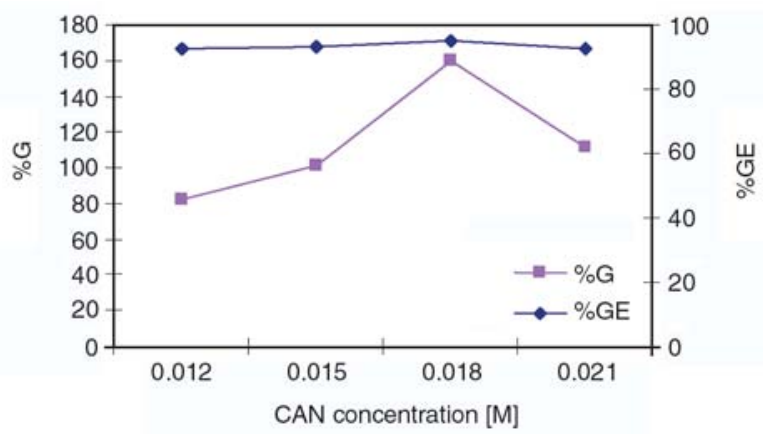

Figure 2. Effect of CAN concentration on $\% \mathrm{G}$ and $\% \mathrm{GE}$

ceric ions exclusively participate in the formation of active sites on the cellulose up to this concentration of ceric ions, and beyond it, no more active sites are formed on the cellulose. Further increase in CAN concentration is accompanied by a decrease in the $\% \mathrm{G}$ and $\% \mathrm{GE}$. The decreasing trend in $\% \mathrm{G}$ and $\% \mathrm{GE}$ beyond $0.02 \mathrm{M}$ concentration of ceric ions may be assumed to be due to its participation in the termination reactions with growing homopolymer and propagating chains on the cellulose $[25,26]$.

\subsection{Effect of monomer concentration}

Using $1 \mathrm{hr}$ soaking time of cellulosic material in CAN solution and $0.02 \mathrm{M}$ CAN concentration as optimized above, the effect of variation of monomer concentration was studied and the results are shown in Figure 3. The results show that as the monomer concentration increases from 12.3 to $30.7 \mathrm{~mol} / \mathrm{AGU}$, there is an increase in $\% \mathrm{G}$, reaching a maximum value of $168.3 \%$ at $24.6 \mathrm{~mol} / \mathrm{AGU}$ and shows decreasing trend with further increase in monomer concentration. Similarly, at acrylonitrile concentration of $24.6 \mathrm{~mol} / \mathrm{AGU}, \% \mathrm{GE}$ reaches a maximum value of $95.8 \%$. Thereafter, there is a decrease in $\% \mathrm{GE}$ with increase in acrylonitrile concentration.

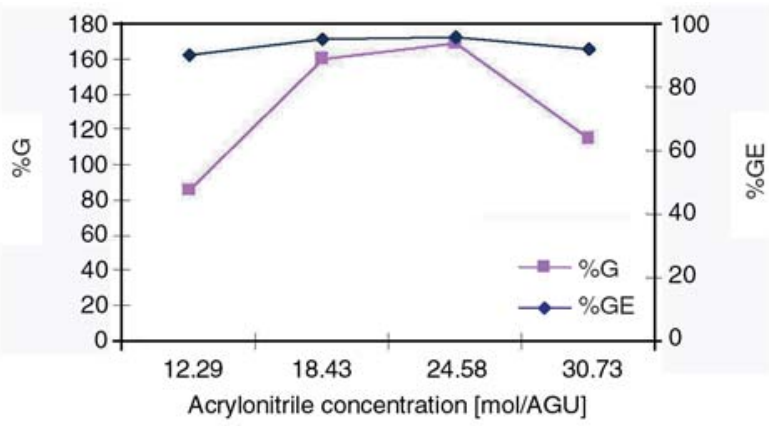

Figure 3. Effect of acrylonitrile concentration on $\% \mathrm{G}$ and $\% \mathrm{GE}$
The enhancement of $\% \mathrm{G}$ and $\% \mathrm{GE}$ by increasing monomer concentration to optimum value could be ascribed to the greater availability of monomer to grafting sites. However, the decreasing trend of $\% \mathrm{G}$ and $\% \mathrm{GE}$ beyond optimum monomer concentration may be due to the competition between homopolymerization and graft copolymerization, where the former prevails over the latter at higher acrylonitrile concentration [26-28].

\subsection{Effect of temperature}

The grafting reactions were carried out at different temperatures $\left(20-50^{\circ} \mathrm{C}\right)$ keeping the other variables constant. The effect of temperature on $\% \mathrm{G}$ and $\%$ GE is shown in Figure 4. Results show that maximum $\% \mathrm{G}(174.8 \%)$ is obtained at $40^{\circ} \mathrm{C}$ and decreases with further increase in temperature. The dependence of $\% \mathrm{G}$ on temperature can be ascribed

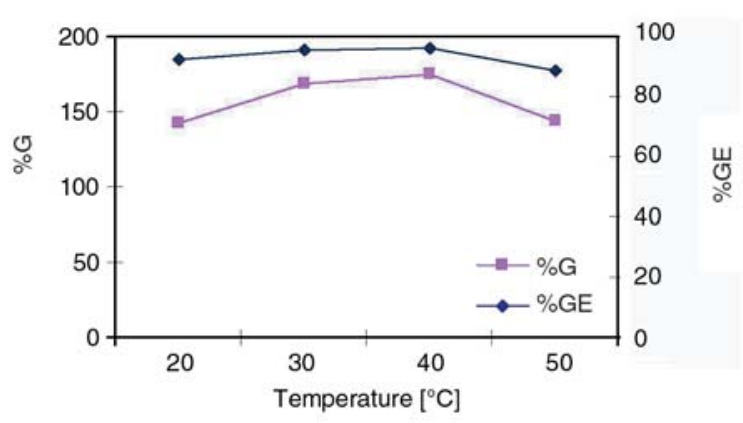

Figure 4. Effect of temperature on $\% \mathrm{G}$ and $\% \mathrm{GE}$

to higher rate of dissociation of initiator as well as the diffusion and mobility of monomer from the aqueous phase to cellulose phase, resulting in considerable improvement in the grafting yield [26, 29]. The $\%$ GE reaches a maximum value of $96.3 \%$ at $40^{\circ} \mathrm{C}$. With further increase of temperature beyond $40^{\circ} \mathrm{C}$, the radical termination reaction might be accelerated, leading to decrease of $\% \mathrm{G}$ as well as $\% \mathrm{GE}$. These findings are in agreement to those reported in literature [23, 26, 29].

\subsection{Effect of duration of polymerization}

Using standardized $1 \mathrm{hr}$ soaking time of cellulosic material in CAN solution of concentration of $0.02 \mathrm{M}$, acrylonitrile concentration $24.6 \mathrm{~mol} / \mathrm{AGU}$ and polymerization temperature $40^{\circ} \mathrm{C}$, the effect of polymerization time on $\% \mathrm{G}$ and $\% \mathrm{GE}$ was studied 


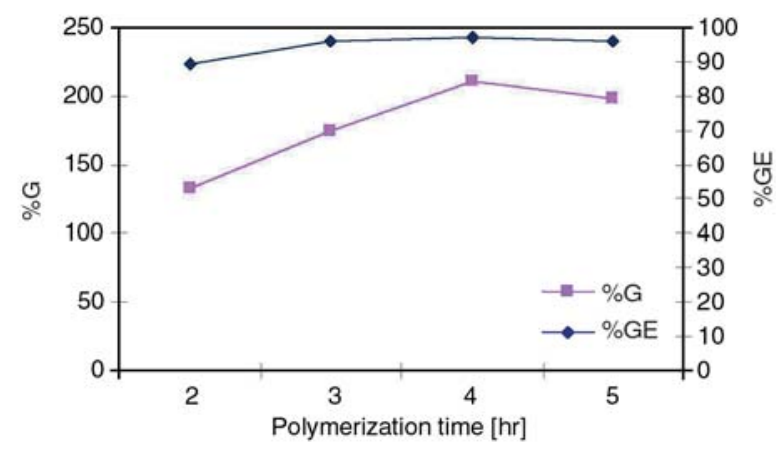

Figure 5. Effect of duration of polymerization on $\% \mathrm{G}$ and $\% \mathrm{GE}$

and the results are shown in Figure 5. It can be seen from the figure that the $\% \mathrm{G}$ increases rapidly with increase in time up to $4 \mathrm{hrs}$, reaching a value $210.3 \%$, after which it levels off. The increase in $\% \mathrm{G}$ is accounted for by the increase in number of grafting sites in the initial stages of reaction due to high rate of ceric ion participation in the formation of reactive sites at the cellulose backbone [25]. Since there is a large excess of acrylonitrile monomer even after the longer reaction times, the leveling off after $4 \mathrm{hrs}$ is presumably due to initiator exhaustion [23]. These observations are in accordance to those observed by Cruz et al. [12], Gupta [25] and Hon [23].

It was also observed that \% GE reaches a maximum value of $97 \%$ at polymerization time of $4 \mathrm{hrs}$. It does not change appreciably on prolonging the polymerization reaction for more than $4 \mathrm{hrs}$. This trend is in conformity of those reported for the grafting of vinyl monomers onto Cassia tora gum [26] and cellulose [30] with ceric ion as redox initiator. Thus, to obtain the maximum $\% \mathrm{G}$, the optimum reaction time is $4 \mathrm{hrs}$.

\subsection{IR characterization}

The FTIR spectra of the cellulosic material derived from bamboo and the optimized grafted sample (\%G 210.3, \%GE 97) were recorded. In the FTIR spectra of the optimized sample of grafted cellulose, besides the typical signals of cellulose backbone $\left(v_{\mathrm{OH}} 3414 \mathrm{~cm}^{-1}\right.$, $v_{\mathrm{CH}} 1431 \mathrm{~cm}^{-1}$, $v_{\mathrm{COC}} 1059 \mathrm{~cm}^{-1}$, $v_{\beta}$-linkage $\left.890 \mathrm{~cm}^{-1}\right)$, the characteristic absorption bands at $2245 \mathrm{~cm}^{-1}$, for the nitrile group $(-\mathrm{C} \equiv \mathrm{N})$ introduced and $2926 \mathrm{~cm}^{-1}$ (characteristic for $-\mathrm{CH}_{2}$ group) with increased intensity were observed, fur-
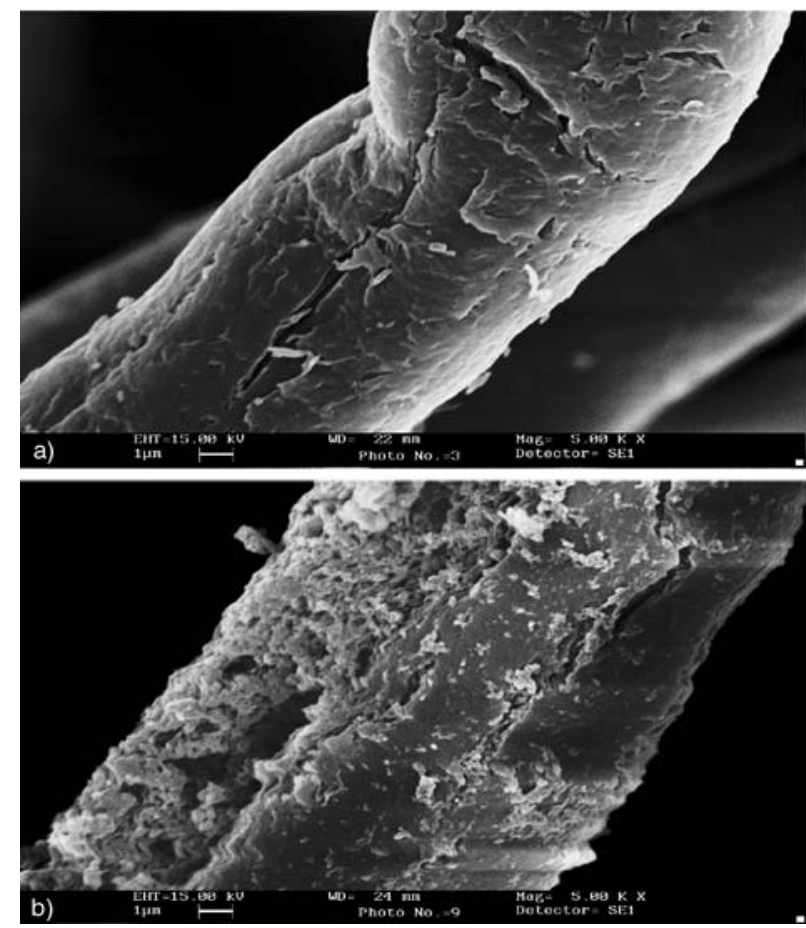

Figure 6. Scanning electron micrographs at 5000 magnification of (a) cellulosic material (b) acrylonitrile grafted cellulosic material

nishing thereby the evidence that grafting of acrylonitrile has occurred.

\subsection{Surface morphology}

SEM images at magnifications 5000 were obtained for parent and grafted cellulosic fibers. Figure 6 depicts the transformation in surface morphology of bamboo fiber on being subjected to grafting with acrylonitrile. The untreated bamboo fiber exhibits a relatively smooth surface compared with the grafted one. Moreover, growth and deposition of the grafted acrylonitrile on the surface and in the intercellular region of the bamboo fiber is clearly visible. Deposition on the surface of fiber resulting in the unevenness of the surface indicated that acrylonitrile was chemically bonded to the surface of the fiber. These results are in accordance to those reported by Cruz et al. [12].

\subsection{Water sorbency}

The WRV of the parent cellulosic material sample was $12.2 \mathrm{~g} / \mathrm{g}$ and of grafted sample was $9.1 \mathrm{~g} / \mathrm{g}$. The WRV decreases on grafting indicating increased hydrophobic nature of the fibers on grafting. These 
findings are in accordance to those reported by Das et al. [21].

\section{Conclusions}

Graft copolymerization of acrylonitrile onto cellulosic material derived from bamboo (Dendrocalamus strictus) (average DP 816) in heterogeneous medium can be initiated effectively with CAN. The optimum reaction conditions obtained for grafting of acrylonitrile onto cellulosic material were: duration of dipping cellulosic material in CAN solution $1 \mathrm{hr}$, CAN concentration $0.02 \mathrm{M}$, acrylonitrile concentration $24.6 \mathrm{~mol} / \mathrm{AGU}$, temperature of reaction $40^{\circ} \mathrm{C}$ and polymerization time $4 \mathrm{hrs}$. The $\% \mathrm{G}$ for optimized samples is $210.3 \%$ and $\% \mathrm{GE}$ is 97 . The characterization of the grafted products by means of FTIR and SEM furnished the evidence of grafting of acrylonitrile onto the cellulosic material.

\section{Acknowledgements}

This study is a part of plan project funded by the Indian Council of Forestry Research \& Education (ICFRE), Dehra Dun. Authors are thankful to the Director, Forest Research Institute, Dehra Dun for encouragement.

\section{References}

[1] Clasen C., Kulicke W-M.: Determination of viscoelastic and rheo-optical material functions of water-soluble cellulose derivatives. Progress in Polymer Science, 26, 1839-1919 (2001).

[2] Barkalow D. G., Young R. A.: Cellulose derivatives derived from pulp and paper mill sludge. Journal of Wood Chemistry and Technology, 5, 293-312 (1985).

[3] Spasojevic L. D., Majdanac L. J., Petrovic S. D., Hrabar J. P., Nesovic V. M., Galovic Z. M., Cvetkovic M. D.: Optimization of carboxymethyl cellulose production. Cellulose Chemistry and Technology, 31, 297-308 (1997).

[4] Akaranta O., Otaigbe J. O. E., Onu C. O., Odozi T. O.: Carboxymethyl cellulose from Musanga ceropioides wood. Cellulose Chemistry and Technology, 22, 315319 (1988).

[5] Patra C. M., Singh B. C.: Influence of N-acetylglycine on the kinetics of the ceric ion-initiated graft copolymerization of acrylonitrile and methyl methacrylate onto jute fibers. Journal of Applied Polymer Science, 52, 1557-1568 (1994).

[6] Patnaik S., Sarangi S., Mohanty A. K., Singh B. C.: Graft copolymerization of acrylonitrile onto jute fibers: Studies on Ce(IV) - hippuric acid redox system. Journal of Applied Polymer Science, 37, 20992107 (1989).
[7] Ghosh P., Ganguly P. K.: Polyacrylonitrile (PAN)grafted jute fibers: Some physical and chemical properties and morphology. Journal of Applied Polymer Science, 52, 77-84 (1994).

[8] Samal R. K., Bhuyan B. L.: Chemical modification of lignocellulosic fibers. 1. Functionality changes and graft polymerization of acrylonitrile onto pineapple leaf fibers - their characterization and behavior. Journal of Applied Polymer Science, 52, 1675-1685 (1994).

[9] Khalil E. M. A., El-Wakil N. A.: Infrared absorption spectra of cyanoethylated cellulose fibres. Cellulose Chemistry and Technology, 34, 473-479 (2000).

[10] Vieira M. C., Heinze T., Antonio-Cruz R., MendozaMartinez A. M.: Cellulose derivatives from cellulosic material isolated from Agave lechuguilla and fourcroydes. Cellulose, 9, 203-212 (2002).

[11] Ramos L. A., Frollini E., Heinze T.: Carboxymethylation of cellulose in the new solvent dimethyl sulphoxide/tetrabutyl ammonium fluoride. Carbohydrate Polymers, 60, 259-267 (2005).

[12] Cruz R. A., Mendoza A. M., Vieira M. C., Heinze T.: Studies on grafting of cellulosic materials isolated from Agave lechuguilla and fourcroydes. Die Angewandte Makromolekulare Chemie, 273, 86-90 (1999).

[13] Tewari D. N.: A monograph on bamboo. International Book Distributors, Dehra Dun (1995).

[14] Ambasta S. P.: The wealth of India: A dictionary of Indian raw materials \& industrial products: Raw materials Vol. 2. B. CSIR Publication, New Delhi (1988).

[15] Hebeish A., Guthrei J. T.: The chemistry and technology of cellulosic copolymers. Springer-Verlag, Berlin (1981).

[16] Gürdag G., Güclü G., Ozgümüs S.: Graft copolymerization of acrylic acid onto cellulose: Effects of pretreatments and crosslinking agent. Journal of Applied Polymer Science, 80, 2267-2272 (2001).

[17] Khullar R., Varshney V. K., Heinze T., Vieira-Nagel, Gupta P. K., Naithani, S., Soni P. L.: Carboxymethylation of cellulose isolated from bamboo (Dendrocalamus strictus) and its rheology. Cellulose Chemistry and Technology, 40, 545-552 (2007).

[18] Khullar R., Varshney V. K., Naithani S., Soni P. L.: Study of the influence of reaction conditions for production of cyanoethylcellulose from cellulosic material derived from bamboo (Dendrocalamus strictus) Journal of Natural Fiber. Accepted for publication (2007).

[19] Khullar R., Varshney V. K., Naithani S., Heinze T., Soni P. L.: Carboxymethylation of cellulosic material (average degree of polymerization 2600) isolated from cotton (Gossypium) linters with respect to degree of substitution and rheological behavior. Journal of Applied Polymer Science, 96, 1477-1482 (2005).

[20] Varshney V. K., Gupta P. K., Naithani S., Khullar R., Bhatt A., Soni P. L.: Carboxymethylation of $\alpha$-cellulose isolated from Lantana camara with respect to degree of substitution and rheological behaviour. Carbohydrate Polymers, 63, 40-45 (2005). 
[21] Das A., Saikia C. N., Hussain S.: Grafting of methyl methacrylate (MMA) onto Anteraea assama silk fiber. Journal of Applied Polymer Science, 81, 2633-2641 (2001).

[22] Gangneux A., Watteiz D., Marechal E.: Synthese et etude de celluloses echangeuses d'ions. Leur emploi dans l'epuration des eaux residuaires de l'industrie textile-1: Synthese d'une cellulose greffee par des chaines poly (acide acrylique) et d'une cellulose renfermant des fonctions ammonium quaternaire. European Polymer Journal, 12, 535-541 (1976).

[23] Hon D. N. S.: Graft copolymerization of lignocellulosic fibers. ACS Symposium Series, Washington (1982).

[24] Kulkarni A. Y., Mehta P. C.: Ceric ion-induced redox polymerization of acrylonitrile on cellulose. Journal of Applied Polymer Science, 12, 1321-1342 (1968).

[25] Gupta S.: Chemical modification of Cassia occidentalis seed gum. Ph.D. Thesis, Forest Research Institute, Dehra Dun, 181-191 (2005)
[26] Sharma B. R., Kumar V., Soni P. L.: Graft copolymerization of acrylonitrile onto Cassia tora gum with ceric ammonium nitrate-nitric acid as redox mixture. Journal of Applied Polymer Science, 90, 129-136 (2003).

[27] Athawale V. D., Vidyagauri V. L.: Graft copolymerization onto starch 3: Grafting of acrylamide using ceric-ion initiation and preparation of its hydrogels. Starch-Stärke, 50, 426-431 (1998).

[28] Hebeish A., Refie M. H. E., Higazy A., Ramadon M.: Synthesis, characterization and properties of polyacrylamide-starch composites. Starch-Stärke, 48, 175-179 (1996).

[29] Heikal S. O., El-Kalyubi S. F.: Graft copolymerization of acrylonitrile onto bagasse and wood pulp. Journal of Applied Polymer Science, 27, 3027-3041 (1982).

[30] Gupta K. C., Sahoo S.: Grafting of acrylonitrile and methyl methacrylate from their binary mixtures on cellulose using ceric ions. Journal of Applied Polymer Science, 79, 767-778 (2001). 